\title{
Block cave ore reserves: Are we reporting a reserve or potential inventory?
}

\author{
N Burgio Stratavision Pty Ltd, Australia
}

\begin{abstract}
Over the past 20 years, block cave operations have pushed the technical frontiers of caving mechanics by mining stronger rock masses, going deeper, extracting taller cave columns and demanding higher productivity rates. The methods and practices for the reporting of block cave ore reserves may not adequately allow for technical uncertainties in these complex and geotechnically challenging conditions. The actual performance of caving operations can vary significantly due to various technical, mining and economic factors. The ability to generate an ore reserves which is convincing has its challenges, particularly at conceptual and pre-feasibility levels when orebody access is generally unavailable to confirm the geotechnical environment that supports the parameters and assumptions that underpin block cave reserves. This paper considers whether current practices meet the guidelines required by industry reporting Codes, and why some operations struggle to meet initial reserve forecasts. Some ideas are offered in how technical risks can be better incorporated into establishing a credible base case scenario.
\end{abstract}

\section{Introduction}

Large-scale mineralised systems amenable to block caving generally have uniform grade distributions (low coefficients of variation) which improves confidence of the resource estimate. The conversion of a resource to reserve, however, requires an emphasis on geotechnically derived modifying factors that include assumptions about caveability and interactive flow behaviour which inherently involve a far greater degree of uncertainty.

Historically, block cave mines were developed in weak rock mass environments requiring extraction of short lift heights $(<250 \mathrm{~m})$. The experiential learnings from these operations have formed the basis of our empirical understanding of caving and flow behaviour. Despite the complexities involved in cave dynamics, it is remarkable that our understanding of material flow can be represented by simplistic empirically derived flow models for reserve estimation. The main reasons tend to be (1) ore was recovered from short lift heights, (2) grade variability is typically low and (3) operations were able to use historical performance to calibrate cave behaviour, ore recovery and dilution predictions.

Over the past two decades, new cave mines have developed at greater depths and in higher stress environments. The significant capital costs required to establish an extraction level results in the need to increase draw heights to maximise tonnage recovery and meet investment criteria. Some operations are, consequently, experiencing more complex and sometimes unpredictable rock mass responses that ultimately impacts ore recovery.

Each block cave mine has its unique geological and geotechnical characteristics, even for adjacent footprints. Understanding the local structural architecture and stress environment is important in assessing caveability, fragmentation, ground stability and subsidence formation. A more consistent approach is required within the industry to demonstrate that adequate analysis has been undertaken within these complex geotechnical environments to support an ore reserve estimate. 


\section{$2 \quad$ Block cave ore reserves}

The conversion of a resource to a reserve requires an appropriate consideration of the modifying factors. These include, but are not restricted to, mining, processing, metallurgical, infrastructure, economic, marketing, legal, environmental, social and governmental factors (AusIMM 2012). However, it can be difficult to define what is "appropriate" when assigning geotechnically derived modifying factors as there are presently no formal guidelines for setting standards or reporting block cave reserves.

Measured resources are generally converted to probable reserves due to the uncertainties related to caveability, mixing and interactive draw (Figure 1). Some projects with access to in-ore development assign proven reserves for areas immediately around the extraction and undercut levels. It is questionable whether quoting proven reserves is appropriate as higher confidence levels at the base of a cave does not necessarily improve recovery predictions, project valuation or a projects risk profile.

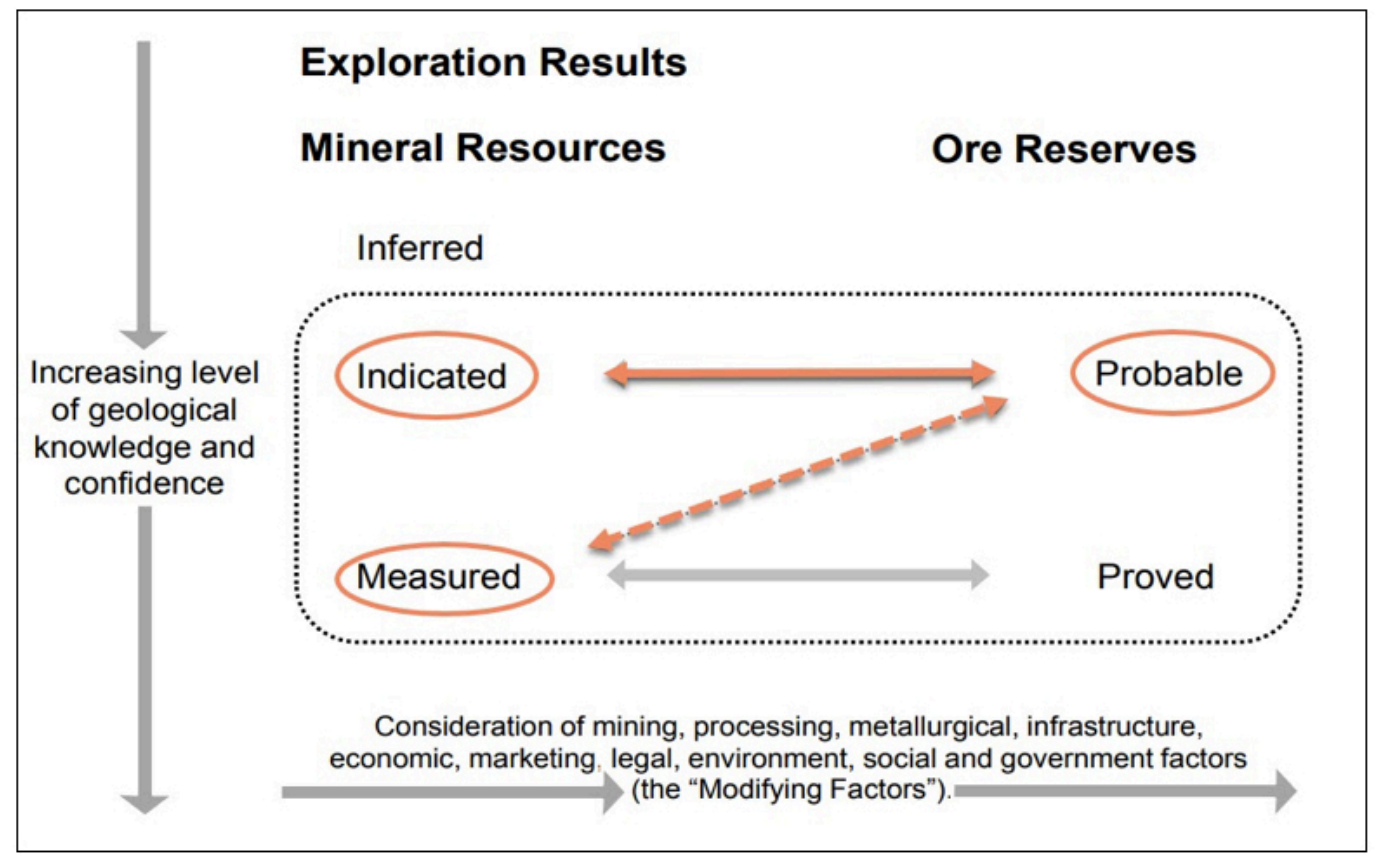

Figure 1 Typical Block cave resource to reserves conversion based on JORC (2012)

Software systems such as PCBC apply empirically derived flow relationships to estimate the amount of mixing (dilution) that is applied. Early versions of this software allowed users to modify mixing parameters based on local geotechnical conditions and expected fragmentation. Over time, additional mechanisms such as rilling, cone erosion and allowances for cave shape, permit models to simulate a more dynamic range of flow mechanisms as well as caving behaviour (Diering 2007). Coupling these systems with more sophisticated numerical models offers a highly effective tool for either predicting flow behaviour or back analysing historical cave performance.

At the pre-feasibility stage block cave reserves generally apply nominal mixing parameters and assume vertical cave growth. As the total orebody knowledge increases more advanced levels of studies improve the reliability of the estimates. Operating mines are able to calibrate historical information and apply actual cave shapes interpreted from monitoring systems to estimate updated reserves. The confidence and reliability of a reserve can therefore vary significantly depending on the approach undertaken. Current reporting practices require a forensic review of the reserves model by a competent person to understand what parameters or assumptions have been applied. For reporting purposes, the level of analysis and assumptions that apply to a reserve estimate need to be more clearly stated in executive summaries. 


\section{Reserves and geotechnics}

Geotechnical evaluations for caving operations typically begin with empirical assessments then advance to numerical modelling simulations. However, whilst the results are used to assist with mine design and planning, there is less focus towards addressing how modifying factors impact reserves. The main areas of concern in terms of risk to ore recovery are:

- Integrity (stability) of the extraction level

- Cave propagation

- Drawpoint spacing

\subsection{Integrity of the extraction level}

The stability and integrity of the extraction level is essential in ensuring recovery of the stated reserves. Most operations undertake geotechnical analysis to determine layouts, drawpoint spacings and ground support measures. However, rarely is this information used to assess the impact on ore recovery, particularly for studies in the pre-production phase.

Severe ground convergence can result in temporary or permanent drawpoint closures which impacts mixing behaviour, dilution ingress and ore recovery. For pre-feasibility level studies, it is important to understand the range of plausible outcomes that are possible to assess the sensitivity of a project. Numerical modelling techniques can offer useful insights to the potential vulnerability of the production level. The trend towards mining deeper and extracting higher ore columns makes such modelling practices increasingly necessary.

As an example, the stability, stress conditions and likely rock mass response for the Kwanika project was simulated using a discontinuum softening dilatant finite element (DFE) model (Beck 2019). This analysis used the benchmarking performance of drawpoints based on the 50th percentile recovery of damage (PR50). The results indicate that higher levels of rock mass damage are expected across the western side of the footprint due to low rock strengths caused by supergene alteration (Figure 2). Mean expected recoveries were estimated based on damage and exclude underbreak, early dilution and stoppages due to wet muck.
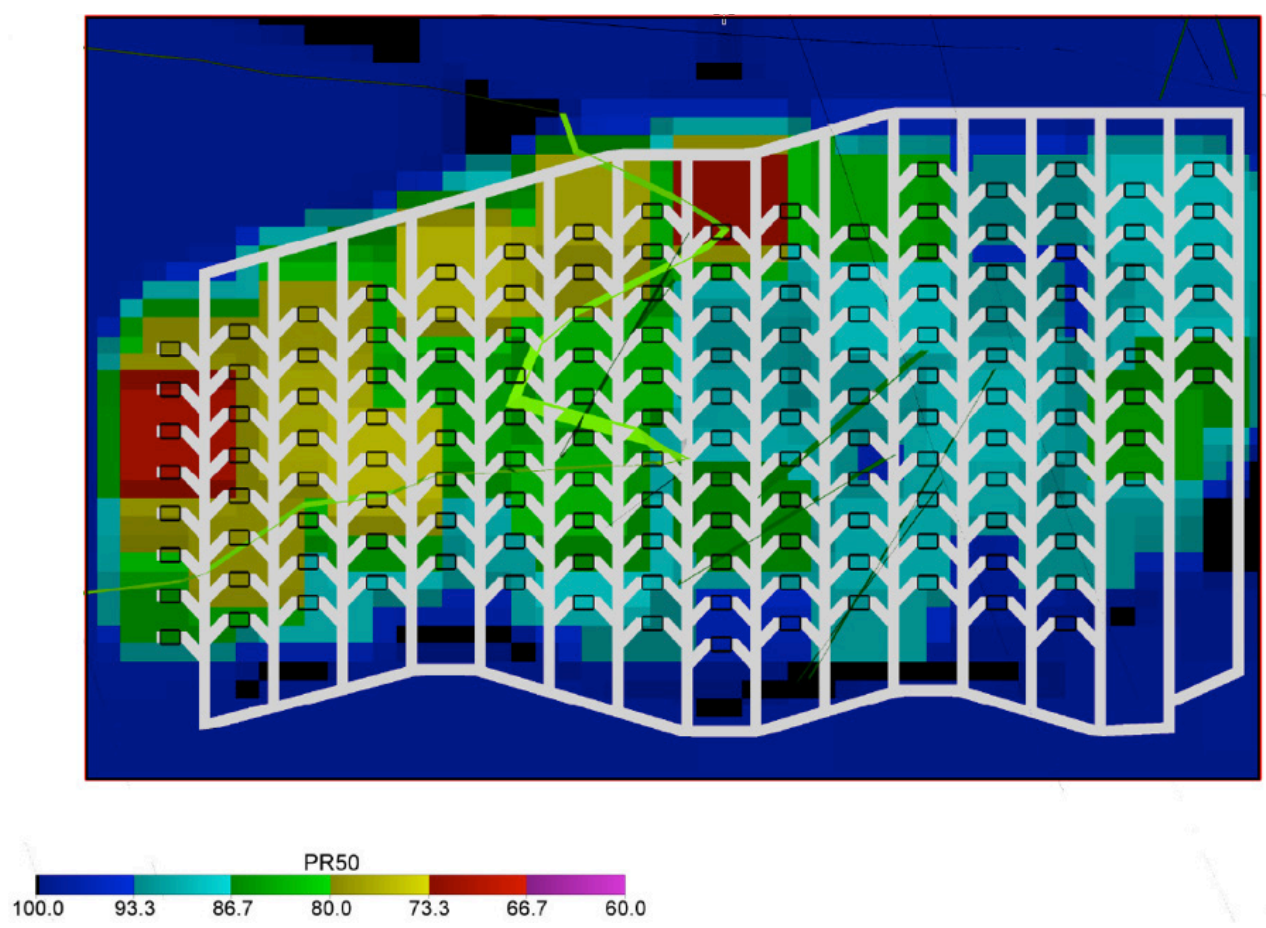

I

Figure 2 Kwanika mean expected recovery (Beck 2019) 
Preliminary estimations using PCBC indicated that the reserve recovery factor was approximately $90 \%$. The DFE analysis agrees with the PCBC parameters for the eastern half of the footprint. However, the numerical model suggests lower recoveries are likely across the western side. The relationship between stress and rock strength indicates that a few drawpoints are vulnerable and may not recover their reserves inventory. This information is particularly useful for it can be used to:

- Assess the potential impact on ore recovery,

- Select the drawpoint layout,

- Refine ground support measures,

- Quantify sensitivity analysis and risk assessments,

- Plan geotechnical monitoring programs, and

- $\quad$ Review mining method.

\subsection{Cave propagation}

Caving studies at the conceptual level rely on empirical assessments of caveability to determine if the proposed mining spans are adequate. Whilst mining spans may satisfy caveability, this does not necessarily suggest the total block cave reserve inventory above a footprint can be converted to reserves. Cave propagation with a direct or indirect connection to surface is an essential requirement for ore recovery. Most block cave reserves are estimated on the assumption the cave will propagate vertically, which is less certain for small footprints with very tall draw columns.

Irregular or incomplete cave propagation can occur in various forms and are referred to as underbreaks, overhangs or cave arrest scenarios (Figure 3). Examples of underbreak are evident at Northparkes E26L2N (Talu 2010), Ridgeway Deeps (Lett et al. 2012), and Cadia East (Lett et al. 2016). By contrast, overbreak is suspected at New Afton due to the ingress of weaker rock mass unit (Parsons \& Hamilton 2018).

The Caving Aspect Ratio (CAR) is, here, defined as the ratio between the height of draw and the average minimum span. As a general guide, mining footprints with a CAR $>1.5$ are more prone to irregular cave propagation behaviour. Such projects should be addressing caveability, not only in terms of satisfying the minimum hydraulic radius, but by also analysing and applying cave propagation predictions to the ore reserve estimate.

If the structural architecture and geotechnical environment are well understood, then indicative cave arrest scenarios can be more confidently modelled. It is important to consider whether underbreak is temporary or permanent. Some operations apply preconditioning measures (hydrofracturing/blasting) to assist cave propagation and enhance ore recovery. These methods have been shown to be effective at Cadia East (PC1) in propagating the cave 1,000 m although some underbreak remains evident.

Mine plans that adopt a panel cave or macroblock mining sequence comprising of adjoining block caves footprints are less prone to ore loss. However, this depends on the relative timing and draw strategy between adjacent macroblocks. Incremental expansions to existing block cave footprints tend to result in partial ore recovery, as evidenced at Northparkes E26 L2N. Efforts to mobilise non-caved areas generally result in limited success due to the preferential flow of highly mobile fragmented cave material which stagnates new cave growth.

Side wall overhangs can result in positive grade reconciliations during the first few years of production due to more material being drawn from the central high-grade areas. Grade forecast at later stages become less predictable, particularly if there are sharp grade contacts or the cave is located under mined areas.

Adjustments to reserves due to incomplete cave propagation are usually made once cave monitoring has confirmed the actual cave response. Numerical modelling techniques can offer useful insights on likely cave propagation behaviour provided these models are supported by representative geotechnical 
and geological inputs. A good understanding of the orientation and characteristics of major faults is an essential requirement to support these models. Systems like PCBC (template mixing) allow cave shapes to be incorporated into the reserve estimate to improve reconciliation and production forecasts. The Ridgeway Deeps block cave was one of the first examples where ore reserves were based on a predetermined cave arrest scenario prior to the commencement of mining (Burgio et al. 2008). There are, however, relatively few examples of operations that make allowances for incomplete recovery due to cave propagation at pre-feasibility and feasibility level studies.

In the modern context, defining cave propagation behaviour is an important component of the caveability assessment, particularly where high draw columns are to be extracted. Exceeding the minimum span requirements to induce caving is only the first step towards addressing whether resources can be fully converted to reserves.

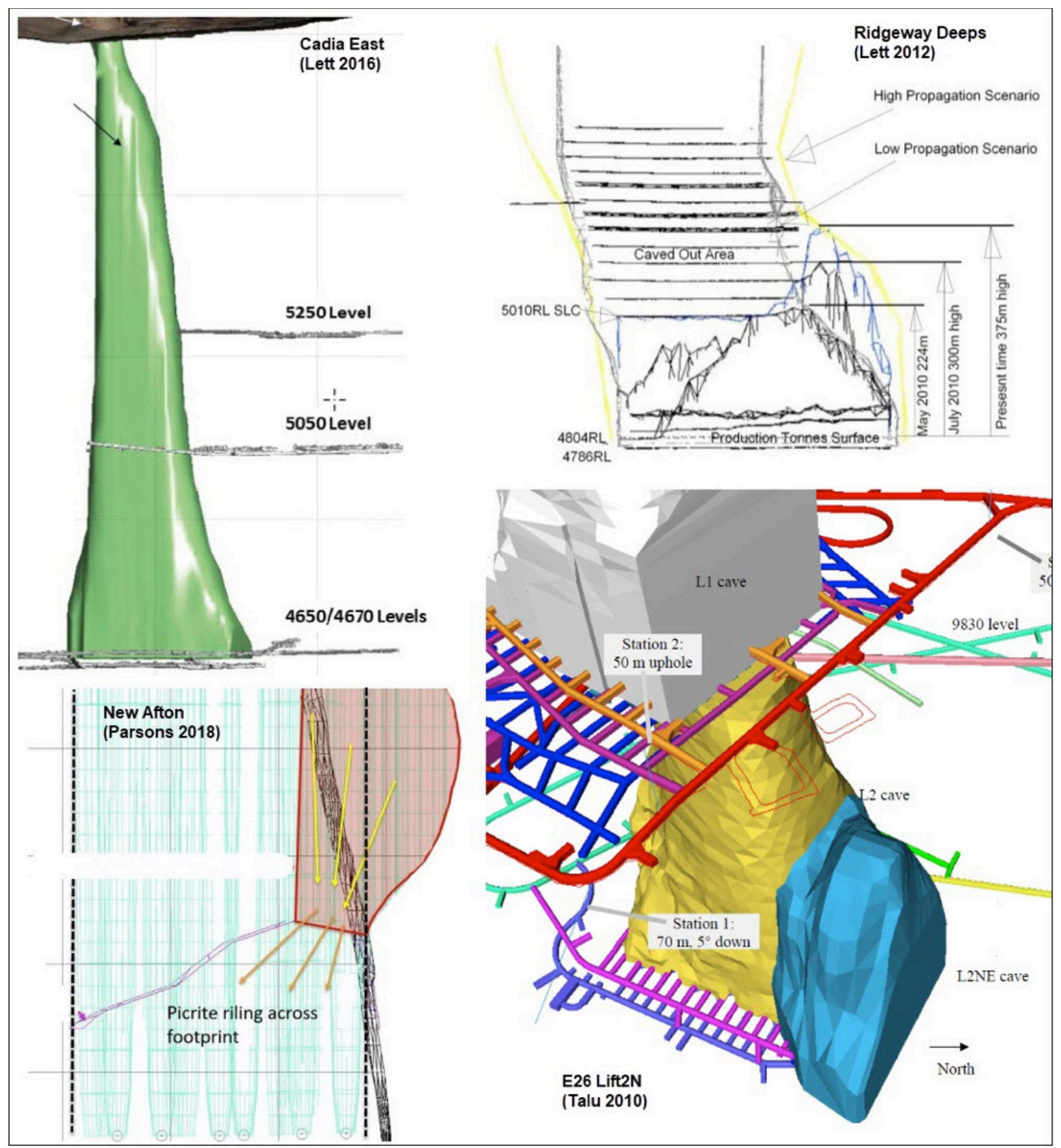

Figure 3 Examples of underbreak and overbreak 


\subsection{Drawpoint spacing}

The impact of dilution in block caves become more apparent during the later stages of a drawpoints production period. Empirical caving theory provides general guidelines to the degree of dilution that is likely to be included. However, actual flow behaviour is more complicated than these simplistic models suggest and can never be determined with absolute accuracy. More sophisticated flow models such as Cellular automata coupled with continuum codes offer opportunities to analyse plausible cave responses (Herbert et al. 2018).

Fortunately, changes to mixing (dilution) parameters only have marginal impacts on reserves, particularly for orebodies with heights of draw $>500 \mathrm{~m}$. A significant change in grade behaviour is not observed during the early stages of draw i.e "if we mixed high grade material with similar high grade material we still end up with high grade material" (Diering et al. 2018). In general, the uniform distribution of mineralisation provides a predictable forecast for ore recovery, especially during the first half of a drawpoints production period. Forecasting grade recoveries towards the later stages of production, however, becomes increasingly difficult.

Design parameters such as drawpoint spacings need to satisfy two important design criteria, namely stability and interactive draw. These issues come into conflict in geotechnically challenging conditions. Ultimately the integrity of the extraction level takes precedence over interactive draw. It is, however, rare to see examples where some discounting has been applied to ore recovery due to undesirable drawpoint spacings. Fragmentation is recognised as an important parameter in the performance of a caving operation and forms the basis of cone theory and interactive draw (Van As et al. 2008). This is the subject of considerable debate as monitoring systems suggest more complex flow mechanisms in the near and far fields (Brunton et al. 2016). It is, nevertheless, important that reserve statements clearly state what flow modelling assumptions have been applied and whether allowances have been applied where interactive draw and recovery is potentially compromised due to widely spaced drawpoints.

\section{$4 \quad$ Establishing a base case}

Current industry practice suggests that reserves quoted at the pre-production stage are generally optimistic i.e, dilution provisions are nominal and ore recoveries, in many cases, implicitly assume vertical cave growth. Each drawpoint is, therefore, expected to eventually yield its total allocated reserves inventory. Projects using these assumptions are at risk of quoting reserves that are optimistic. It is questionable whether these models qualify as credible "base-case" scenarios for comparing mining options, making investment decisions, and setting credible risk assessment outcomes.

A plausible base case scenario needs to incorporate realistic assumptions about caveability, flow and ore recovery with some upside and downside potential. In situations where no advanced modelling is available, which is often the case at conceptual or pre-feasibility level studies, block cave practitioners need to apply realistic expectations in terms of recovery.

By way of example, consider a caving project planned at a depth of 1,000 m below surface (Project identity is not provided due to confidentiality). The rocks are of moderate strength in a range between $50-80 \mathrm{MPa}$ due to intense alteration. Geotechnical risks appear to increase with depth due to unfavourable stress to strength ratios evidenced as by high levels of core disking. The layout comprises of 1902 drawpoints to be sequenced as a panel cave and is required to extract $500 \mathrm{~m}$ high draw columns. Drilling information suggests that rock mass conditions are generally uniform except for an area towards the southeast side which appears to be impacted by faulting. A base case scenario was established based on the assumption that $30 \%$ of the total number of drawpoints (570/1902) would likely recover $50 \%$ of their available PCBC estimated reserves. In the absence of geotechnical modelling the locations of the affected drawpoints were chosen at random, except for the area deemed to be fault impacted (Figure 4). This scenario is referred to as the discounted recovery model. 
Figure 5 shows the Best Height of Draw (BHOD) for the original and discounted models as modelled by $P C B C$. The initial reserves inventory, based on nominal dilution parameters was estimated to be approximately 650 MTonnes. The discounted recovery model resulted in a $18 \%$ reduction in tonnage due to the shortened heights of draw and is thought to represents a more credible scenario for reserves estimation despite the obvious unknowns about the actual timing and location of the areas impacted (Figure 5). The discounted model also provides a more realistic position to consider plausible upside opportunities and downside risks. The results also have direct consequences for ramp up rates, number of drawpoints required to maintain steady stage production, and the timing of transitions to other mining areas.

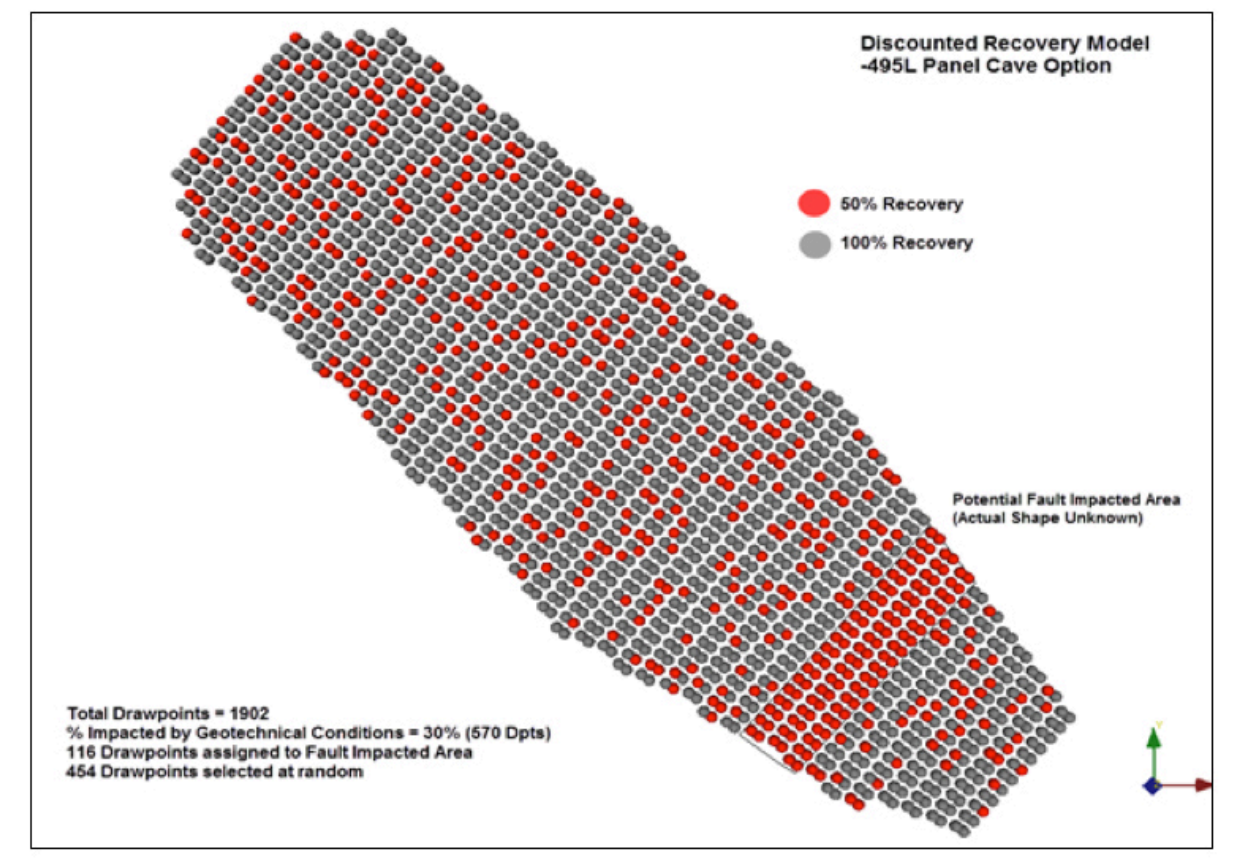

Figure 4 Example of a discounted recovery model applied within PCBC

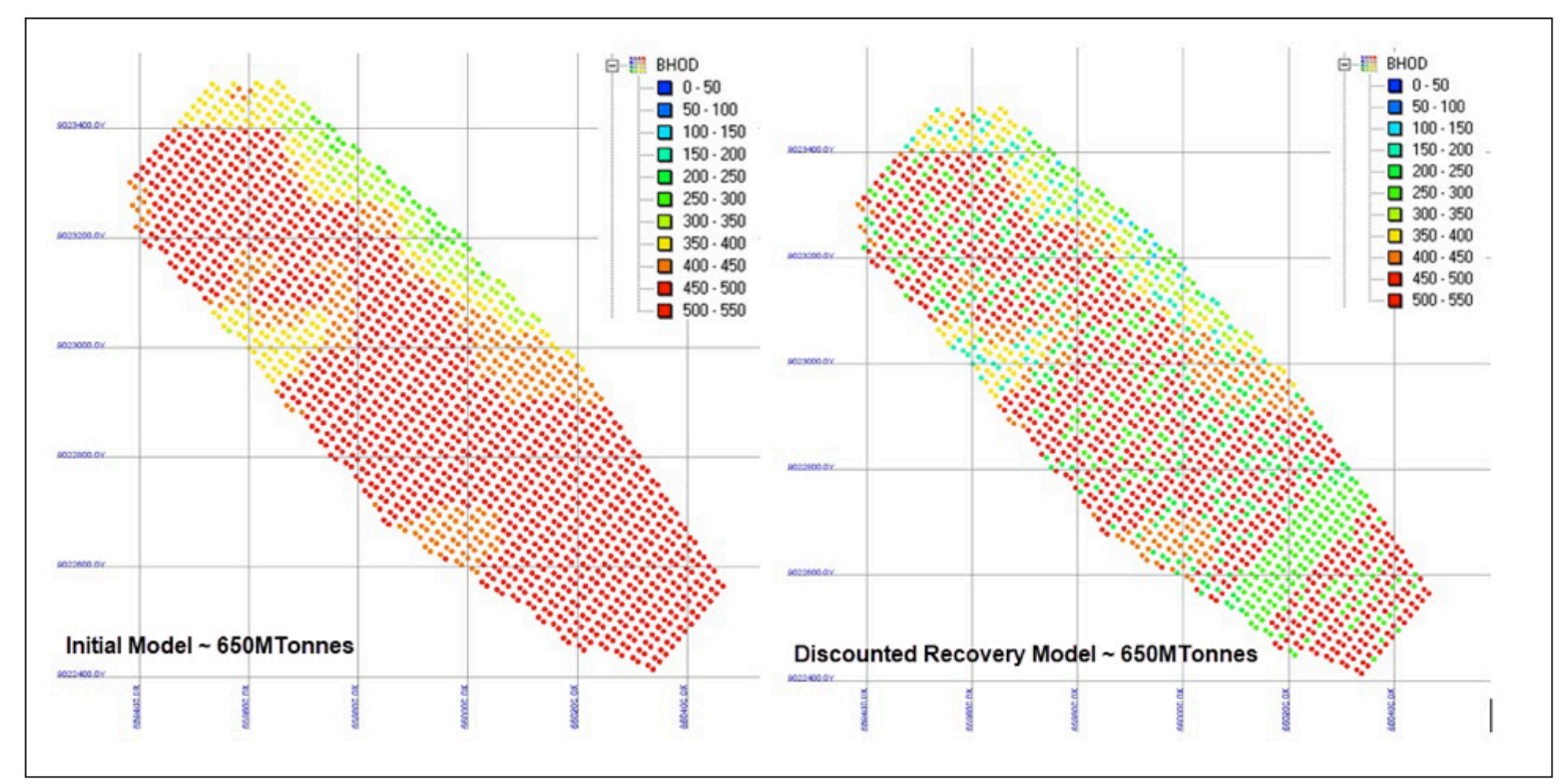

Figure 5 PCBC derived best height of draw comparison (BHOD) between initial and discounted recovery models 


\section{$5 \quad$ Technical requirements for Block cave reserves}

The JORC code requires certain information to be disclosed concerning the mining factors and assumptions used in the estimation of a reserve. The factors relevant to this discussion are outlined in Table 1.

\section{Table 1 Block cave reserve considerations}

\begin{tabular}{|c|c|}
\hline Reserve considerations & Studies and inputs \\
\hline \multirow{3}{*}{$\begin{array}{l}\text { Appropriateness of the } \\
\text { selected mining method }\end{array}$} & Caveability assessments (Empirical and Numerical analysis) \\
\hline & Fragmentation analysis \\
\hline & Cave Interaction issues with pre-existing mined areas \\
\hline \multirow{4}{*}{$\begin{array}{l}\text { Assumptions made } \\
\text { regarding geotechnical } \\
\text { parameters }\end{array}$} & Stability of extraction level \\
\hline & Pillar stability \\
\hline & Drawpoint layout and orientation \\
\hline & Standoff distances for critical infrastructure \\
\hline \multirow{3}{*}{$\begin{array}{c}\text { Mining dilution factors } \\
\text { used }\end{array}$} & Drawpoint spacing \\
\hline & Mixing parameters applied \\
\hline & Proportion of external dilution in reserve \\
\hline \multirow{4}{*}{$\begin{array}{l}\text { Mining recovery factors } \\
\text { used }\end{array}$} & Draw cone shapes/interactive draw \\
\hline & Cave shapes \\
\hline & Cave propagation assumptions \\
\hline & Drawpoint availability \\
\hline
\end{tabular}

Caveability assessments are typically undertaken to assess whether the mining geometry is sufficient to induce natural caving. However, for mining blocks with CAR $>1.5$, additional modelling may be required to demonstrate that the ore reserve is fully recoverable. Technical reports need to include a discussion on cave propagation and clearly state the assumptions that have been applied. Mining blocks positioned underneath pre-existing mine out areas need to also state any special consideration has been given towards modelling the behaviour of fines material and how they impact dilution. Caves that are planned in high stress environments, or where the stress to strength ratios are unfavourable, need to demonstrate that appropriate modifying factors have been applied to drawpoint availability and recoverable reserves.

\section{Conclusions}

A block cave ore reserve should incorporate reasonable expectations regarding cave behaviour, dilution and ore recovery based on local geotechnical conditions. Projects planned in geotechnically challenging rock mass environments need to consider impacts such as drawpoint availability, cave propagation behaviour and dilution ingress from pre-mined areas. Block cave reserve software systems such as PCBC allows predicted or actual cave propagation behaviour to be simulated to improve flow predictions and assess impacts to ore recovery. Numerical modelling, supported by a good understanding of the structural and geotechnical environment, is an essential requirement to enable realistic modifying factors to be included in the ore reserve. In the absence of these models, it is important to apply an appropriate level of discounting to establish more credible and plausible base case scenarios.

Examples of irregular cave propagation behaviour are becoming more frequent and have direct impact on ore recovery. Improved guidelines and reporting transparency are required, particularly as projects advance into deeper and more complicated geotechnical environments. Without this, the industry stands the risk of quoting reserves based on overly optimistic assumptions. 


\section{Acknowledgements}

The writer wishes to acknowledge Serengeti Resources and Beck Engineering for permitting to use their project and technical information.

\section{References}

AusIMM, AIG \& MCA 2012, 'Australian Code for Reporting of Exploration Results, Mineral Resources and Ore Reserves', Joint Ore Reserves Committee of the Australian Institute of Mining and Metallurgy, Australian Institute of Geoscientists and Minerals Council of Australia (JORC).

Beck, D 2019, Simulation of Potential Subsidence, internal report, Serengeti Resources, Vancouver.

Brunton, I, Lett, JL, Sharrock,GB, Thornhill, T \& Mobolio, B 2016, 'Full-scale Flo marker Experiments at the Ridgeway Deeps and Cadia East Cave Operations', in C Carr \& G Chitombo (eds), Proceedings of MassMin 2016, The Australian Institute of Mining and Metallurgy, Sydney, pp. 141-159.

Burgio, N \& Diering, T 2008 'Simulating irregular cave propagation using PCBC' Proceedings of Massmin 2008, Luea University of Technology, Lulea, pp. 1033-1042.

Diering, T Ngidi,S, Bezuidenhout,J, \& Paetzold, H 2018 ' Palabora Lift 1 block cave: understanding the grade behaviour', Caving 2018 Proceedings of the Fourth International Symposium on Block and Sublevel Caving, pp. 91-106, Vancouver, Canada.

Diering, T 2007, 'Template mixing: A depletion engine for block cave scheduling' in EJ Magri (ed.), Proceedings of the 33rd International Symposium on Application of Computers and Operations Research in the Mineral Industry, pp. 313-320, Gecamin, Santiago.

Herbert,Y \& Sharrock,G 2018 ' Three-dimensional simulation of cave initiation, propagation and surface subsidence using coupled finite difference-cellular automata solution', Caving 2018 Proceedings of the Fourth International Symposium on Block and Sublevel Caving, pp. 151-166, Vancouver, Canada.

JORC Code 2012, Australian Code for Reporting of Exploration Results, Mineral Resources and Ore Reserves.

Lett, JL, Brunton, I, Capes, GW, Jäger, A, Mobilio, B, Rachocki, J, Sharrock, GB \& Secheny, M 2016, 'Undercutting to surface breakthrough - Cadia East Panel S. Talu, Rio Tinto, Australia.

Lett, JL \& Capes, GW 2012, Characterisation of Caving and Subsidence for operational enhancements at the Newcrest Ridgeway Gold Mine, Proceedings of Massmin 2012, Canadian Institute of Mining, Metallurgy and Petroleum, Westmount.

Parsons, J, Hamilton, D 2018, 'Non-vertical cave and dilution modelling at New Gold's New Afton Mine', Caving 2018 Proceedings of the Fourth International Symposium on Block and Sublevel Caving, pp. 323-334, Vancouver, Canada.

Talu, S, Van As, A, Seloka, W \& Henry, R 2010, 'Lift 2 North extension cave performance', Caving 2010 Second International Symposium on Block and Sublevel Caving, Australian Centre for Geomechanics, Rio Tinto, Australia.

Van As, A., Seloka, W. \& Henry,H. 2010, ' Lift 2 North extension cave performance', Caving 2010 Second International Symposium on Block and Sublevel Caving, Australian Centre for Geomechanics Cave, Proceedings of MassMin 2016, The Australasian Institute of Mining and Metallurgy, Melbourne, pp. 65-82.

Van As, A \& Van Hout, G, J 2008 'Implications for widely spaced drawpoints', Proceedings of Massmin 2008, Lulea University of Technology, Lulea, pp. 147-154. 